\title{
Chapter 24 \\ Innovative Strategy for Addressing the Challenges of Monitoring Off-Shore Wind Turbines for Condition-Based Maintenance
}

\author{
Amin Al-Habaibeh, Ampea Boateng, and Hyunjoo Lee
}

\begin{abstract}
Off-shore wind energy technology is considered to be one of the most important renewable energy source in the 21 st century towards reducing carbon emission and providing the electricity needed to power our cities. However, due to being installed away from the shore, ensuring availability and performing maintenance procedures could be an expensive and time consuming task. Condition Based Maintenance (CBM) could play an important role in enhancing the payback period on investment and avoiding unexpected failures that could reduce the available capacity and increase maintenance costs. Due to being at distance from the shore, it is difficult to transfer high frequency data in real time and because of this data transferring issue, only low frequency-average SCADA data (Supervisory Control And Data Acquisition) is available for condition monitoring. Another problem when monitoring wind energy is the massive variation in weather conditions (e.g. wind speed and direction), which could produce a wide range of operational alerts and warnings. This paper presents a novel case study of integrated event-based wind turbine alerts with time-based sensory data from the SCADA system to perform a condition monitoring strategy to categorise health conditions. The initial results presented in this paper, using vibration levels of the drive train, indicate that the suggested monitoring strategy could be implemented to develop an effective condition monitoring system.
\end{abstract}

Keywords Wind turbines - Condition monitoring, Condition-Based maintenance • $\mathrm{CBM} \cdot \mathrm{SCADA}$

A. Al-Habaibeh ( $\square)$

Product Innovation Centre, Nottingham Trent University, Nottingham, UK

e-mail: Amin.Al-Habaibeh@ntu.ac.uk

A. Boateng $\cdot \mathrm{H}$. Lee

Offshore Renewable Energy Catapult, Blyth, Northumberland, UK 


\subsection{Introduction}

Due to the growth in the world's population, worldwide energy demand is on the increase [1]. The Paris Agreement to lessen the impact of climate change sets the target of keeping the global temperature increase below $2{ }^{\circ} \mathrm{C}$ of the pre-industrial stage [2]. The UK Government's Climate Change Act (2008) creates a target of reducing greenhouse gas emissions to $80 \%$ of the 1990 level by the year 2050 [3], this focuses the attention on renewables as the way forward. Wind turbine technology is well established for onshore and offshore. Onshore wind energy systems have their own limitations, particularly near homes, in relation to noise, shadow flicker; and also, in the countryside due to the possible effect on wildlife and the potential negative aesthetic impact [4]. Hence, this makes offshore wind energy farms a suitable option due to scalability and the reduced effect on residential areas and wildlife. But this comes with its own challenges, as the cost of maintenance could be expensive and the reduction in capacity due to faults could be significant. According to [5], 28\% of installed wind turbine capacity in Europe is expected to be older than 15 years by 2020 . As wind turbines reach the end of their designed service life, maintenance of aging assets become critical to ensure return on investment and availability of capacity. This makes CBM an important concept to ensure maintenance can be done with suitable TPM (Total Productive Maintenance) strategy. A recent survey of CBM of wind turbines have indicated that new models and methodologies are needed which will allow adaptive maintenance scheduling and the prediction of time-to-failure through prognostics and health asset management [6].

\subsection{The Case Study}

Figure 24.1 presents a schematic diagram of the offshore wind energy turbine used in this case study. The wind turbine in consideration is a $7 \mathrm{MW}$ system with rotor diameter of circa 171 metres and standard hub height of about $110 \mathrm{~m}$ above mean sea level. It has rotation direction of clockwise looking downwind with minimum rotor speed of $5.9 \mathrm{rpm}$ and rated rotor speed of about $10.6 \mathrm{rpm}$. The cut-in wind speed is $3.5 \mathrm{~m} / \mathrm{s}$ and the cut-out wind speed is $25 \mathrm{~m} / \mathrm{s}$ with rated wind speed of $13 \mathrm{~m} / \mathrm{s}$. The three blades are bolted on a pitch bearings which are connected to a hub. The hub is attached to the main low speed shaft to transfer the torque to the gear box. The gearbox increases the speed of the output shaft to a suitable rpm to power the generator to produce three phase electricity. Blade pitch angles are continuously controlled depending on wind speed conditions above the rated speed. It also provides an aerodynamic braking when stopping procedures of the control system is activated. The main shaft and the gearbox are rigidly supported by two main bearings. The main shaft takes the torque and other loads from the rotor and its supporting configurations and transmits the pure torque to the gearbox. The system has an integrated and compact drive train design with oil lubrication for the gearbox and the main bearings 


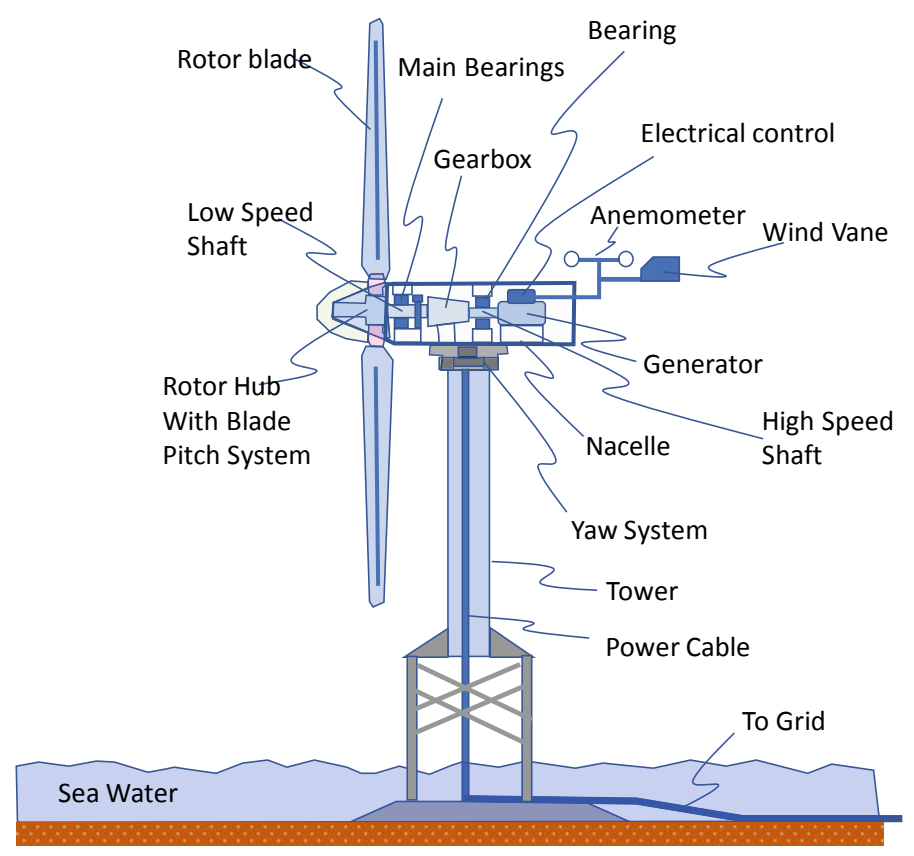

Fig. 24.1 A schematic diagram of the offshore wind energy turbine used in this case study

to enhance reliability. Rotor brake unit will stop the rotor speed following a deceleration by the aerodynamic braking systems via the orientation of the blades. Also there is a rotor locking system using with automatic or manual actuation. The generator, with nominal rotation speed of $400 \mathrm{rpm}$, is based on permanent magnet generator to provide higher efficiency. The electric generator is cooled using air-to-water cooling system and connected to the grid via a convertor.

\subsection{Condition Monitoring and SCADA Data}

The time history data provided by the SCADA system includes variables such as time, rotor speed, forces and torques at the hub centre and vibration of the gearbox. For ambient conditions, variables such as air temperature, wind direction and speed are captured, including nacelle temperature. For the grid, voltage, current, power and frequency are monitored. For the gearbox, sensors to monitor vibration, oil level, oil temperature and oil pressure are installed. Sensors for stress levels and vibration are also installed on bearings and near blade roots. The average data from the sensors are captured in the form of sensory feature characteristic (SCF) such as average, maximum, minimum and standard deviation. SCADA fault or waning system will also register the error of fault at the moment it happens via the control as ON or OFF status. 
Figure 24.2 presents some examples of the data captured during operation (as a 10 min period) and Fig. 24.3 presents examples of how sensory data and alert data are registered during operation.

From Fig. 24.2 it is evident that the turbine has experienced wind speed less than $3.5 \mathrm{~m} / \mathrm{s}$ during different periods of time in the figure (e.g. sample number 3500 ) which caused the rotor to stop and the power generation to drop to zero. It is clear that if there is no rotation, vibration levels will also drop to zero. Note that the fluctuation in wind speed produces high average vibration levels and in the power generated. But during that time there has been many alerts and warning within the independent SCADA system.
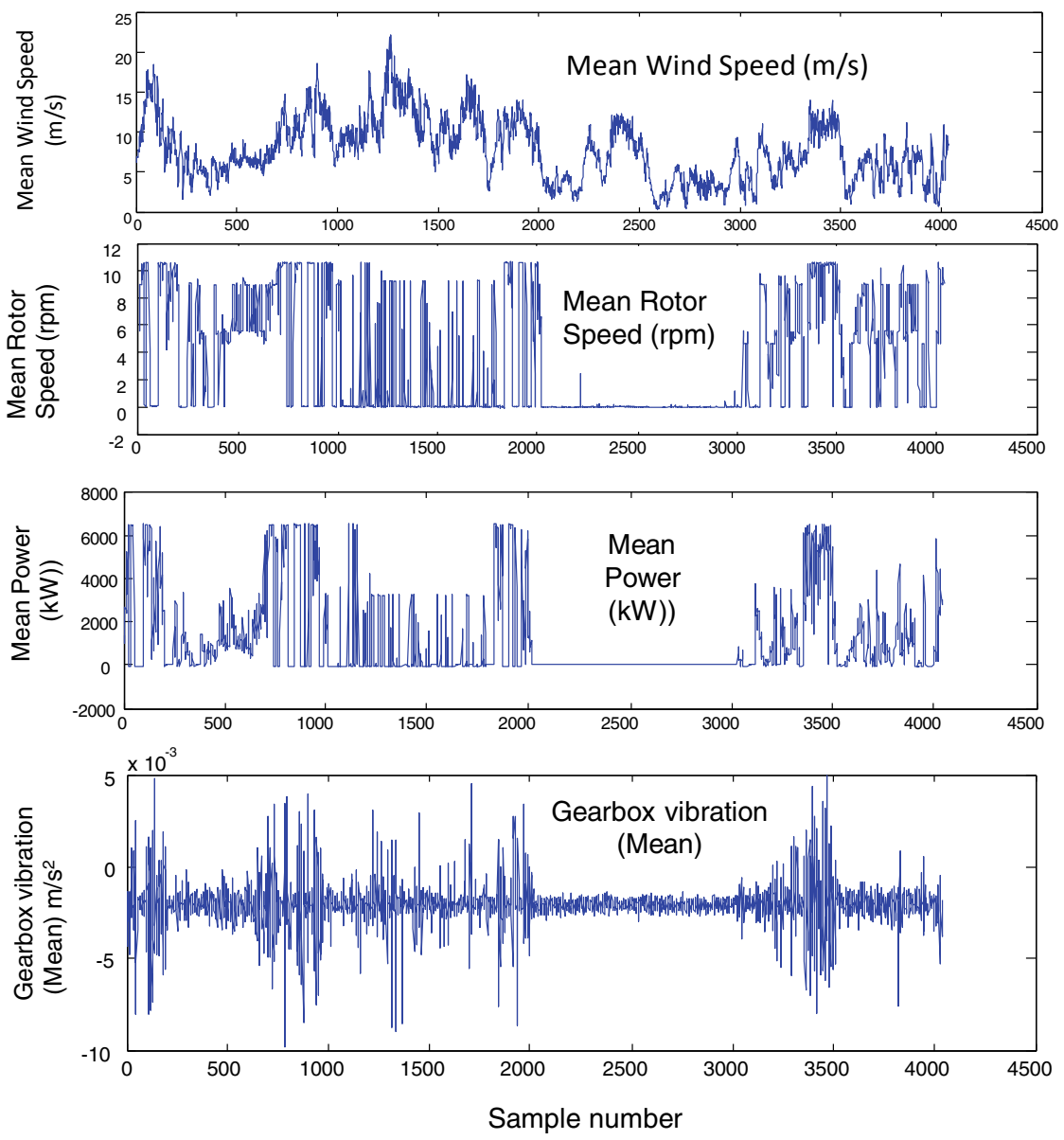

Fig. 24.2 Examples of the data in relation to wind speed, rotor speed, power generated and gearbox vibration 


\begin{tabular}{|c|c|c|c|c|c|}
\hline \\
\hline x_Startiime & $\begin{array}{c}\text { WindSpeed__ } \\
\text { mps_Mean }\end{array}$ & $\begin{array}{l}\text { WindSpeed_mp } \\
\text { s.stdev }\end{array}$ & $\begin{array}{l}\text { Rotorspeed_rpm } \\
\text { Mean }\end{array}$ & $\begin{array}{c}\text { RotorSpeed_rpm } \\
\text { Stdev }\end{array}$ & $\begin{array}{l}\text { Nacelle Orientation } \\
\text { Deg_Min }\end{array}$ \\
\hline 07/01/201900:00 & 6.370099441 & 0.753717761 & 8.966484134 & 0.227632815 & 216.112 \\
\hline 07/01/201900:10 & 6.180607961 & 0.714575458 & 7.198205017 & 1.658076885 & 224.0059 \\
\hline 07/01/201900:20 & 6.331067486 & 0.538305239 & 5.596074492 & 0.129179038 & 224.0072 \\
\hline 07/01/2019 00:30 & 6.72016821 & 0.573542969 & 5.593674458 & 0.131812148 & 224.0072 \\
\hline 07/01/201900:40 & 6.942188706 & 0.77170168 & 7.71696081 & 1.634554206 & 224.0059 \\
\hline 07/01/201900:50 & 6.771846741 & 0.894997826 & 8.994795418 & 0.222648755 & 224.0059 \\
\hline 07/01/201901:00 & 7.484857397 & 0.819880329 & 8.984588782 & 0.210233846 & 224.0059 \\
\hline & 7.054135905 & & $\begin{array}{l}8.90 .97651875 \\
8.9765\end{array}$ & 0.209021978 & 224.0059 \\
\hline 07/01/201901:20 & $\begin{array}{l}7.054353055 \\
7.004002306\end{array}$ & 1.091950075 & $\begin{array}{l}8.9677187136 \\
8.9672736\end{array}$ & $\begin{array}{l}0.207649735 \\
0.2075\end{array}$ & 224.0059 \\
\hline 07/01/201901:30 & 7.68446681 & 1.115288492 & 9.018011423 & 0.234656298 & 224.0059 \\
\hline 07/01/201901:40 & 7.630248966 & 1.012675852 & 8.982554951 & 0.188780785 & 224.0059 \\
\hline 07/01/2019 01:50 & 7.733771401 & 1.060284336 & 9.040768199 & 0.21788103 & 224.0046 \\
\hline 07/01/201902:00 & 8.988599418 & 1.081412888 & 9.898310209 & 0.415122059 & 224.0059 \\
\hline 07/01/2019 02:10 & 8.462902151 & 1.063256988 & 9.412734406 & 0.321010496 & 224.0059 \\
\hline
\end{tabular}

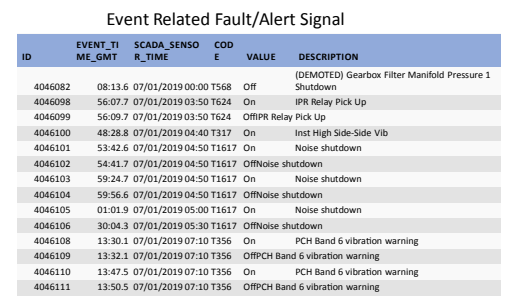

Fig. 24.3 Example of the time related sensory signals and Event related fault/alert signal

\subsection{Sensory and Alarm Integration Procedure}

In order to integrate the sensory data at a specific interval of every $10 \mathrm{~min}$ for example (see Fig. 24.4a), and the alert or error messages of the SCADA system (Fig. 24.4b), which could happen and be deactivated at any time, this paper suggests an integration process outlined by a generic example and articulated in Fig. 24.4c, d.

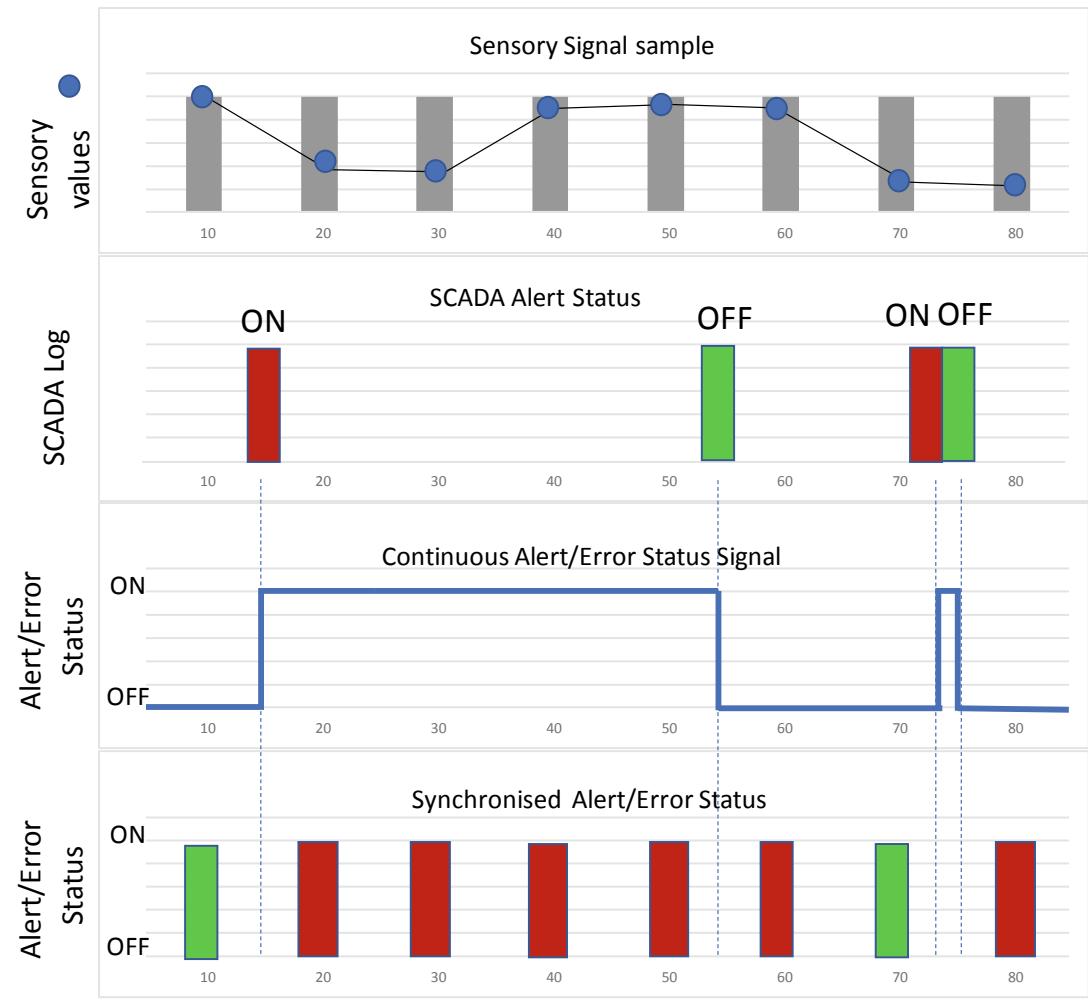

(a)

(b)

(c)

Sample time (minutes)

Fig. 24.4 Synchronisation principle of SCADA Alert/Error Status and Sensory signals 
Based on the sensory data of Fig. 24.4a and the event-based warning in Fig. 24.4b, c presents a continuous function that is generated from the discrete alert system of Fig. 24.4b. The principle of this approach is that the alert or fault status is assumed $\mathrm{ON}$ or active, until an OFF or deactivation signal if found. If during the same time period the alert or error is activated and then deactivated, in this case the alert status is assumed active for that period and then deactivated for the following periods. Hence, the principle of the integration is: if the last status of the alert is active, then the alert will continue for the following periods until deactivation is observed. If activation and deactivation happen in the same period, then for that period the status will be active and will be considered re-activated for the following period, see Fig. 24.4.

\subsection{Discussion: Time-Based and Event-Based Data Integration Case Study}

Figure 24.5 presents an experimental case study to test the algorithm of the data integration to transfer a vibration alert which is event-based to be synchronised with time-based associated data. Figure 24.5a presents the alert time as it was transferred from SCADA system and processed using the suggested approach of Fig. 24.4. To validate the methodology, the average vibration sensor of the gearbox and the
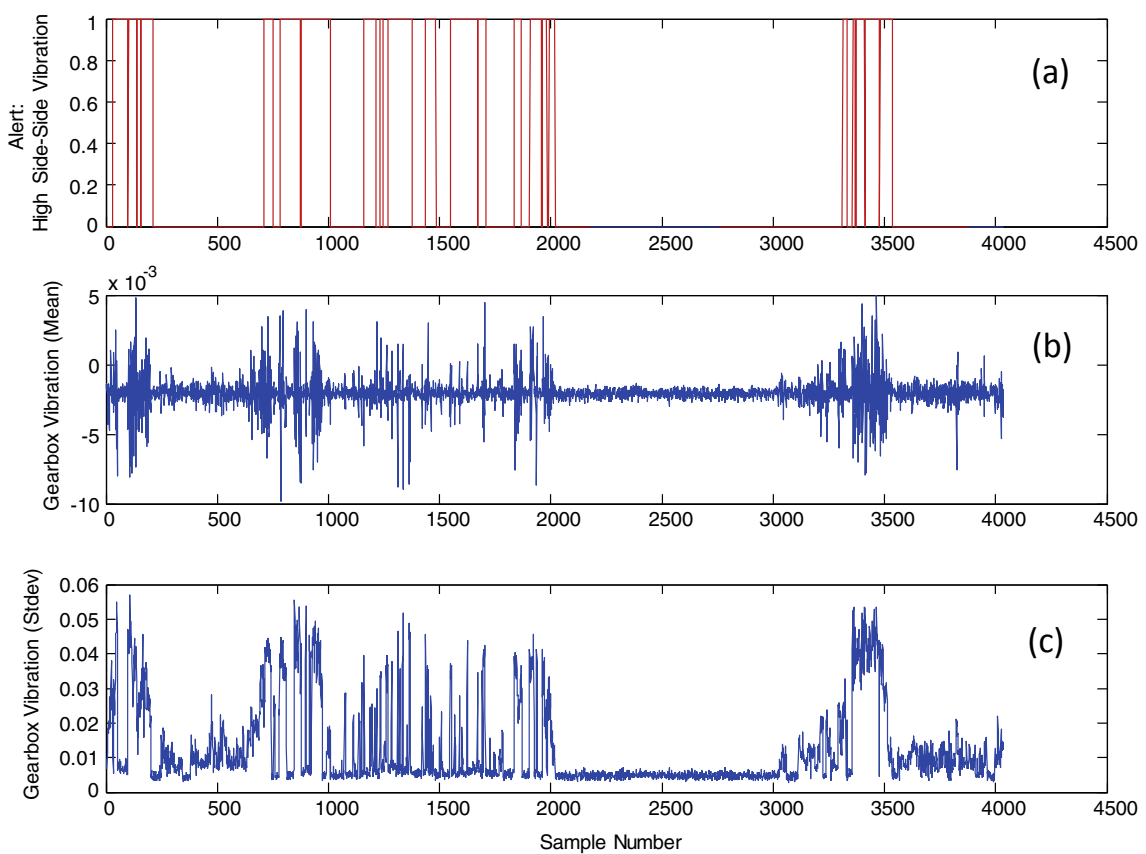

Fig. 24.5 Case study of vibration alert and the vibration signals of the gearbox 
standard deviation of the vibration levels, Fig. 24.5b, c respectively, are compared with the transferred and processed alert/error signal. It is evident that the integration was synchronised as shown in Fig. 24.5 and the alert/error occurs when the vibration level of the gearbox reaches higher than norm levels. When comparing Fig. 24.2 with Fig. 24.5, it is evident that fluctuation in wind speed and rotor speed is what is causing the alert and the high level of vibrations.

\subsection{Conclusion}

This paper has suggested an integration methodology which allows the development of a Condition-Based Monitoring system by transferring event-based system errors and alerts to the time domain to be synchronised with the sampled data from the sensors. From the presented data, high fluctuation in wind speed is found to cause fluctuation in power generation and rotor speed which would cause high vibration levels in the drive train and hence a vibration alert. Future work will involve using Artificial Intelligence techniques to learn from experience to allow self-learning diagnostic of health conditions and future prognostics of wind turbines.

Acknowledgements The authors would like to thank Innovate UK and EPSRC for funding this research work; grant Reference EP/S515711/1.

\section{References}

1. U.S. Energy Information Administration, “International Energy Outlook 2017,” 2017. Accessed: Nov. 28, 2017. [Online]. https://www.eia.gov/outlooks/ieo/pdf/0484(2017).pdf

2. United Nations Framework Convention on Climate Change, "ADOPTION OF THE PARIS AGREEMENT-Paris Agreement text English." United Nations, Paris, pp. 1-27, 2015, Accessed: Jul. 19, 2017. [Online]. https://unfccc.int/files/essential_background/convention/app lication/pdf/english_paris_agreement.pdf

3. Climate Change Act. London: The Parliament of the United Kingdom, pp. 1-103 (2008)

4. Heather Thomson, Willett Kempton, Perceptions and attitudes of residents living near a wind turbine compared with those living near a coal power plant, Renewable Energy, Volume 123, pp. 301-311, ISSN 0960-1481 (2018)

5. Suzan Alaswad, Yisha Xiang, A review on condition-based maintenance optimization models for stochastically deteriorating system, Reliability Engineering \& System Safety, Volume 157, pp. 54-63 (2017), ISSN 0951-8320. https://doi.org/10.1016/j.ress.2016.08.009 
Open Access This chapter is licensed under the terms of the Creative Commons Attribution 4.0 International License (http://creativecommons.org/licenses/by/4.0/), which permits use, sharing, adaptation, distribution and reproduction in any medium or format, as long as you give appropriate credit to the original author(s) and the source, provide a link to the Creative Commons license and indicate if changes were made.

The images or other third party material in this chapter are included in the chapter's Creative Commons license, unless indicated otherwise in a credit line to the material. If material is not included in the chapter's Creative Commons license and your intended use is not permitted by statutory regulation or exceeds the permitted use, you will need to obtain permission directly from the copyright holder.

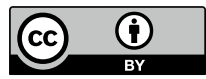

